\title{
A Prototype of Smart Agriculture System Using Internet of Thing Based on Blynk Application Platform
}

\author{
Badri Narayan Mohapatra ${ }^{1}$, Rohan Vilas Jadhav ${ }^{2}$, and Ketan Sunil Kharat ${ }^{2}$ \\ ${ }^{1}$ AISSMS Institute of Information Technology, Pune,411001, INDIA \\ ${ }^{2}$ Department of Instrumentation, Sri Savitribai Pule Pune University, Pune, 411001, INDIA \\ Corresponding author: Badri Narayan Mohapatra (e-mail: badri1.mohapatra@gmail.com or badri.mohapatra@aissmsioit.org).
}

I would like to thank AISSMS IOIT undergraduate students for the complete timely collection and compilation of results in the research work of their project. I have appreciated their motivation towards this research project.

\begin{abstract}
Due to smart operation between the physical and digital worlds, peoples shows that there is huge interest in IoT systems. Today IoT devices are very user-friendly and easy to access with less power and network connectivity. This research presents the use of the Internet of Things in monitoring crops and for other agricultural purposes. The field of agriculture has always demanded high standards of resources, professionalism, and effort. Today, the majority of the world depends on agriculture for food consumption, economic growth, trade, and employment. It also comes with various sets of challenges for agriculturists. Various agriculturists, farmers, and scientists across the globe believe in formulating different plans and ideas to deal with these challenges. The smart farming system is based on the fastest growing Internet of Things (IoT) technology which will be cheaper, more productive, and cost-effective. In this research, we focus on handling various information about the crops under consideration by undertaking requisite commands from the user for better management of crops and their allied resources, hence providing a robust and useful facility for agriculturists across various domains. This research also promotes further exploration of the use of electronics and internet technology in the field of farming and agriculture.
\end{abstract}

INDEX TERMS Agriculture, Blynk app, IoT, NodeMCU, Soil Sensor

\section{INTRODUCTION}

With the increasing population and growing demand for food, there is a big challenge to increase productivity. Very few farmers are adopted such new techniques, but still, the count is very limited. An integrated system deals with all elements influencing profitability. The method aims to make horticulture excellent by efficiently utilizing computerization and IoT, which uses GPS-based remote-controlled robots to perform fieldwork such as weeding, splashing, dampness detecting, winged creature and creature startling, keeping carefulness, and so forth [1]. This gives $98 \%$ of the accurate data using the live agricultural stick tested on Live Agriculture Fields [2]. It uses the concept of IoT and data mining, solves the current problem of farming methodologies, and provides practical solutions [3].

The quality and quantity of crops depend on different parameters like climate, soil characteristics, available nutrients, and the quantity of irrigation. Climate change is the prime factor of threat for farmers and is very important for the adaption of new strategies and making security on productivity. IoT in agriculture increases the productivity of existing food production systems and improves food security. Other facilities such as crop monitoring, weed monitoring can also be done through using trending technologies like IoT [4]. Food demand within a limited area is a very big challenge [5]. The new era of agriculture is like the fourth revolution named Farming 4.0 [6]. Advanced IoT 
technologies have restructured the existing farming techniques like statistical to quantitative approaches [7]. Changes in humidity, temperature, and soil moisture have an impact on crop yield. So control, protection, and monitoring have become important to farming industries. The Indian economy mainly depends on agriculture. By taking appropriate adoption of IoT technology can improve the farm output. An emerging application of IoT is widely used fully in different sectors like manufacturing, buildings, transportation as well as farming industry.

\section{PROPOSED WORK}

The objective of this research is to build a model that can provide an efficient decision support system using the ESP8266 WiFi Module, which handles different activities of the farm and gives useful information about different parameters related to the crops under observation through wireless connectivity on an electronic device. These parameters include air humidity, atmospheric temperature, soil moisture, etc. The model is also required to take necessary actions like turning the water pump on or off when required or when desired through an instruction given by the user over the electronic device interface.

The model uses a GPS module to easily retrieve location information that measures the different agricultural parameters. For e.g., the quality of soil helps in determining the nutrient value in drier areas of farms, and soil acidity allows adjusting the amount of water needed for irrigation.

TABLE 1

loT for Agriculture case study

\begin{tabular}{|c|c|c|c|}
\hline $\begin{array}{l}\text { Sr. } \\
\text { No }\end{array}$ & Research Paper & Features & Benefits \\
\hline 1 & $\begin{array}{l}\text { IoT based smart } \\
\text { agriculture [8] }\end{array}$ & $\begin{array}{l}\text { Using Automation in } \\
\text { IoT and GPS remote } \\
\text { robot system. }\end{array}$ & $\begin{array}{l}\text { Accurate data } \\
\text { prediction }\end{array}$ \\
\hline 2 & $\begin{array}{l}\text { IoT in agriculture } \\
\text { [9] }\end{array}$ & $\begin{array}{l}\text { Through the help of } \\
\text { Markov chain, it gives } \\
\text { an idea about what a } \\
\text { crop is suited for. }\end{array}$ & $\begin{array}{l}\text { Use of IR and } \\
\text { DM concept }\end{array}$ \\
\hline 3 & $\begin{array}{l}\text { IoT based smart } \\
\text { agriculture stick [10] }\end{array}$ & $\begin{array}{l}\text { Getting an accurate } \\
\text { live feed of the } \\
\text { environment } \\
\text { temperature and soil } \\
\text { moisture. }\end{array}$ & $\begin{array}{l}\text { Know the } \\
\text { condition of } \\
\text { environmental } \\
\text { parameters }\end{array}$ \\
\hline 4 & $\begin{array}{l}\text { Farming using IoT } \\
{[11]}\end{array}$ & $\begin{array}{l}\text { Use of sensors and by } \\
\text { enabling automation } \\
\text { concept. }\end{array}$ & $\begin{array}{l}\text { Helpful in } \\
\text { making } \\
\text { decisions }\end{array}$ \\
\hline 5 & $\begin{array}{l}\text { Dynamic irrigation } \\
{[12]}\end{array}$ & $\begin{array}{l}\text { GSM/GPRS protocol } \\
\text { to develop a low-cost } \\
\text { information } \\
\text { monitoring system for } \\
\text { smart farming. }\end{array}$ & $\begin{array}{l}\text { Efficient water } \\
\text { management }\end{array}$ \\
\hline
\end{tabular}

The system contains two sensors, one is the Soil Moisture sensor, and the other is an IR sensor, apart from other components that include an ESP8266 WiFi Module, Relay, and Water Pump. The readings from the sensor are displayed in the Arduino IDE software and are notified in the form of a message in the Blynk app on Mobile. IR sensor helps to Homepage: jeeemi.org

Vol. 4, No. 1, January 2022, pp: 24-28 sense the presence of any unnecessary insects or wildlife in the field near to the sensor, so this will be used as smart security system [13].

Soil sensors are mostly used in agriculture, landscape irrigation, and as simple sensors for gardeners. Nowadays, robots can perform different tasks in the farming sector [12]. Automated agricultural robots have some issues in real-time performance [14]. Before implementing a sensor, its performance can be checked in the Tinkercad simulation tool[15-16].

\section{A. SENSORS IN AGRISYSTEMS}

A sensor monitors parameters like soil moisture, humidity, soil temperature, and others that play an essential role in crop production activity. Pollination and plants' leaf growth depends mainly on humidity which is easily sensed by a humidity sensor. The accurate amount of nutrients for which $\mathrm{pH}$ is necessary, water level, and quality are also very important in agriculture. Sensors also help in vertical farming system and become very successful [17].

\section{B. COMMUNICATION TECHNOLOGIES}

For communication with trending devices, one should use Bluetooth, WiFi, ZigBee, LoRa, or RFID. But the frequency bands, as well as the transmission ranges, are different. Considering the cost, $\mathrm{WiFi}$ and LoRa will be higher as compared to others. A solution to the high demand and high consumption of food and to fulfill all significant implementation of ICT which make a valuable impact on the agricultural industry [18].

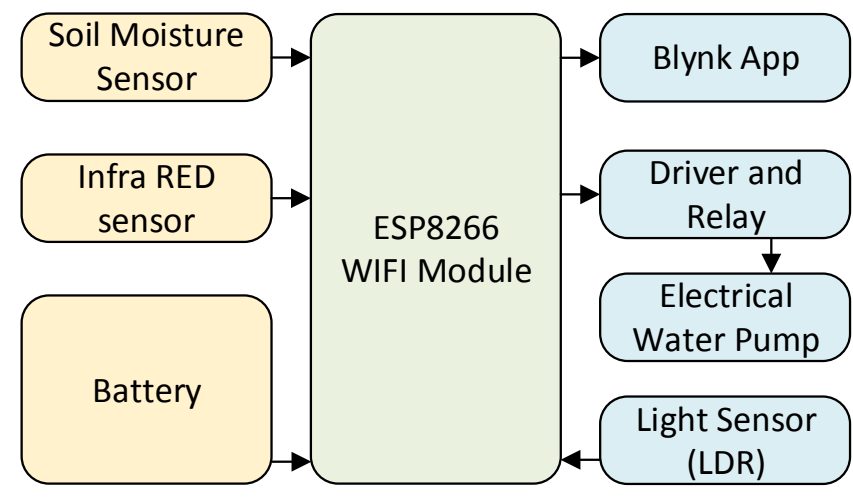

FIGURE 1. Basic block diagram of the Smart Farming System.

\section{HARDWARE}

\section{A. ESP8266}

The ESP8266 is a low-cost ultra-low-power WiFi chipset with a voltage rating of $3.3 \mathrm{~V}$. The ground of the ESP is connected to the ground pin of the Arduino. So temporary WiFi is facilitated, and any data can be displayed since ESP has its own IP Address.

The NodeMCU development kit board v0.9 consists of the ESP8266 chip along with 11 GPIO pins, 4MB flash, one pin 
ADC, two pairs UART, WiFi band $2.4 \mathrm{GHz}$, and supports WPA/WPA2 [19]. Figure 1 explains the basic block diagram representation of the proposed farming system.

\section{B. IR SENSORS}

Infrared sensors are valuable due to their lower mass and passive capability. They're used for surveillance on the ground and as well as in space-based platforms. IR sensor performance characteristics are omnidirectional, so they're widely used in defense and other commercial systems. It is used as the best measurement device in the farming industry [20].

\section{SOIL MOISTURE SENSOR}

Measurement of soil moisture content is done by inexpensive sensors that nowadays are used in gardening and Precision Agriculture. Soil moisture level detection is one of the key aspects as it controls the growth of crops.

\section{RELAY}

Economic activities depend a lot on agriculture, and sustainable smart farming is a way to facilitate the same, for which a relay connection is mandatory. In order to control a circuit, a relay is used as a switch, and it requires $3.75 \mathrm{~V}$ to $6 \mathrm{~V}$ for its operation. Apart from this, pumps and LDRs are also used.

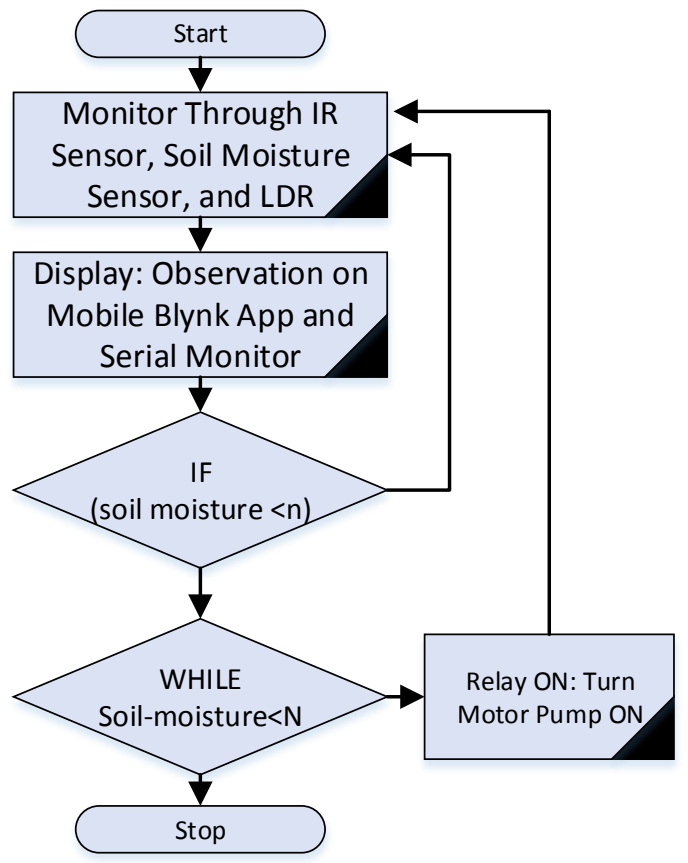

FIGURE 2. Flow chart for smart agriculture.

\section{SOFTWARES}

Arduino IDE (Integrated Development Environment) for Windows is required for implementing the code written in Embedded C language. Blynk app is used for the WiFiServer connection [21]. In general, IDE can be created by
Arduino, and the sketches can be written in $\mathrm{C}$ or $\mathrm{C}++$. Figure 2 informs the flow process which has been implemented here.

\section{RESULTS}

The soil sensor is inserted in the soil to sense whether the soil is wet or dry. A combination of hardware and software together makes an embedded system, and it responds in realtime. Jumper wires are required to make the appropriate connections. The hardware model representation is shown in Figure 3, which is connected with NodeMCU via relay and soil sensor.

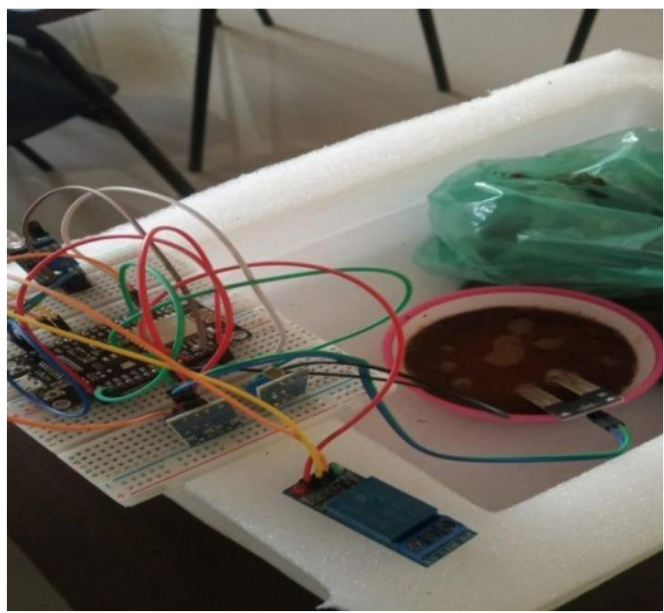

FIGURE 3. Relay connection to NodeMCU for smart farming.

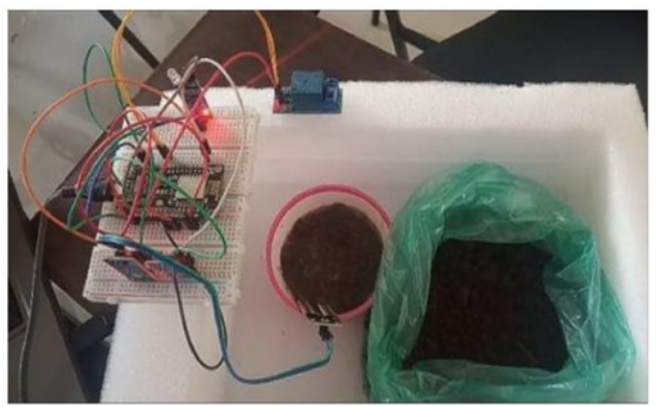

FIGURE 4. Prototype Connection for the Smart Agri System by using NodeMCU and Soilsensor.

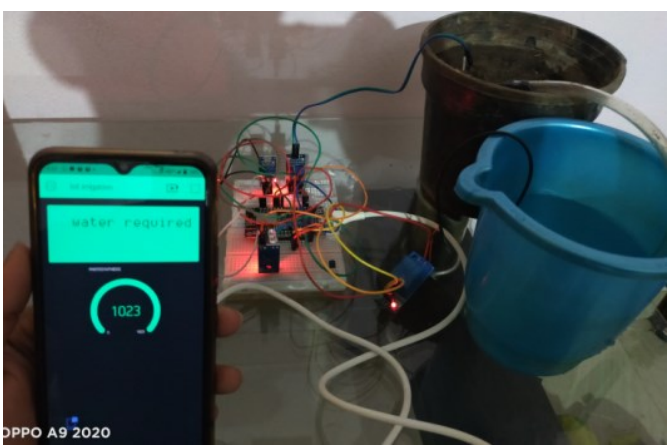

FIGURE 5. Water monitoring display on a Smartphone. 
Arduino programming along with motor operation control is a very good decision support system, which not only helps in reducing the waste of water but is also beneficial for determining the hour when the crop needs water. The suggested actions can be implemented in any weather conditions to make smart precision agriculture; for e.g., when the farming area is required to be irrigated, each information will come to the Smartphone, as shown in FIGURES 4 \& FIGURE 5, or if an animal attempts to enter the farming area or agriculture field it can be monitored through any mobile Smartphone as is shown in FIGURE 6. One can monitor the output of the smart sensor from anywhere by using the internet. The Blynk app does a splendid job in finding, monitoring, and displaying real-time data only within a fraction of time. From the above prototype system, we are assured of Blynk's effective operation and application, and hence the research model is suitable to be implemented in big farming for smart cultivation for improving productivity.

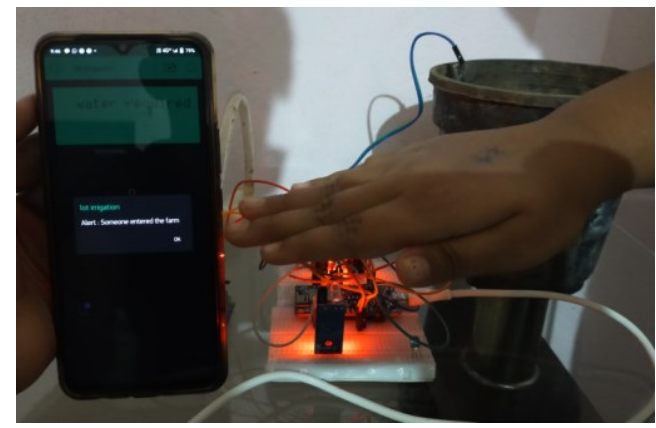

FIGURE 6. Someone entered the farm" alert message displayed

TABLE 2 shows the cost and model which is used in the proto-type research. These results will vary in terms of land area or size, occupancy, location, and environment. As our experiment was conducted for a week to check the accuracy and continuously monitored where data's are automatically reflected in the computer.

TABLE 2

Hardware Cost for Prototype Model

\begin{tabular}{|c|c|c|c|}
\hline $\begin{array}{l}\text { Sr. } \\
\text { No }\end{array}$ & Hardware & Model No & $\begin{array}{c}\text { Cost } \\
\text { (Indian Ruppe) }\end{array}$ \\
\hline 1 & $\begin{array}{l}\text { Soil moisture } \\
\text { sensor }\end{array}$ & REES52 & $100-200$ \\
\hline 2 & IR Sensor & . & $40-50$ \\
\hline 3 & $\begin{array}{l}\text { Nodemcu } \\
\text { Esp8266 }\end{array}$ & $\begin{array}{l}\text { Serial Wireless } \\
\text { Module Ch340 Wifi } \\
\text { Development Board }\end{array}$ & $400-600$ \\
\hline 4 & 5V Relay & 1 Channel. & 70 \\
\hline 5 & $\begin{array}{l}\text { Micro } \\
\text { Submersible } \\
\text { Pump Mini water } \\
\text { pump }\end{array}$ & Micro DC 3-6V & $50-100$ \\
\hline 6 & LDR & & $40-60$ \\
\hline 7 & $\begin{array}{l}\text { Solderless } \\
\text { Breadboard }\end{array}$ & GL-12 840 Points & $100-150$ \\
\hline
\end{tabular}

First of all, farmers need to follow a smart irrigation process like reading the soil moisture measurement estimation like which time the irrigation require to their farming field. Because there may be the generation of two choices like a plant needs water or the soil is dry, so it requires water. So the design should be developed with farmer ideas and predictions about the plant/crop production. Based on that, the system developer can satisfy the farmer by implementing the actual system. This approach provides a good farming service for a smart agriculture system. For this, researchers, scientists and engineers, and manufacturing agencies develop IOT based architecture and enhance crop data management.

Latest development technologies are very real future prospects and recommendations for advanced agriculture. Advanced agriculture consists of three different approaches like monitoring soil, crop, and types of machinery. A second approach like sensor information like temperature, stem, fruit size. Furthermore, the last approach such as fertilizer, pesticides, irrigation, etc. Now Smartphone and IoT technology can change by bridging the rural-urban gap and reducing the limitation on delivering systems.

\section{CONCLUSION}

In this research, we conclude that an agri-environmental monitoring system is possible through a small prototype design model. Even if the model has a lot of advantages, but many big challenges can be listed. First on the list stays the concerns on hardware cost, software cost, and energy optimization. Secondly, the storage of data and reliability. Thirdly, data accessibility and connectivity and fast real-time deployment. No doubt the sensor can give the sensing location and agriculture parameters, but at what position one needs to place and how many sensors are required for a particular land area, details like these should be thoroughly specified. To achieve better efficiency, these are some of the open challenges in modern smart concepts in the agriculture domain. Even after these advancements, there is still a need for awareness in village people about modern agricultural technologies. Modern agriculture practices not only help to improve the farm output but also contribute to the overall welfare of farmers.

Data transmission in poor internet connection can create harsh environment, but in terms of functionality, it enables a diverse range for communication for physical devices. This work opens up new ideas like implementation on a large area, and field installation with power management and skillful, efficient farmer choice farming by deploying farmer required data for using the best algorithm for the good implementation results better productivity. It also helps in best management like water management, crop monitoring also improves time efficiency and minimizes the human efforts. 


\section{REFERENCES}

[1] Gondchawar, Nikesh, and R. S. Kawitkar. "IoT based smart agriculture." International Journal of advanced research in Computer and Communication Engineering 5.6 (2016): 838-842.

[2] Nayyar, Anand, and Vikram Puri. "Smart farming: IoT based smart sensors agriculture stick for live temperature and moisture monitoring using Arduino, cloud computing \& solar technology." Proc. of The International Conference on Communication and Computing Systems (ICCCS-2016). 2016.

[3] Doshi, Jash, Tirthkumar Patel, and Santosh Kumar Bharti. "Smart Farming using IoT, a solution for optimally monitoring farming conditions." Procedia Computer Science 160 (2019): 746-751.

[4] Soni, Gaurav Kumar, et al. "IOT Based Smart Agriculture Monitoring System." Design Engineering (2021): 2243-2253.

[5] Mumtaz, Rafia, Shahbaz Baig, and Iram Fatima. "Analysis of meteorological variations on wheat yield and its estimation using remotely sensed data. A case study of selected districts of Punjab Province, Pakistan (2001-14)." Italian Journal of Agronomy 12.3 (2017).

[6] Lezoche, Mario, et al. "Agri-food 4.0: A survey of the supply chains and technologies for the future agriculture." Computers in Industry 117 (2020): 103187

[7] N. Khan, R. L. Ray, G. R. Sargani, M. Ihtisham, M. Khayyam, en S. Ismail, "Current Progress and Future Prospects of Agriculture Technology: Gateway to Sustainable Agriculture", Sustainability, vol 13, no 9, bl 4883, 2021

[8] Fountas, Spyros, et al. "The future of digital agriculture: technologies and opportunities." IT professional 22.1 (2020): 24-28.

[9] Jamal, Alaa, and Raphael Linker. "Genetic Operator-Based Particle Filter Combined with Markov Chain Monte Carlo for Data Assimilation in a Crop Growth Model." Agriculture 10.12 (2020): 606.

[10] Panigrahi, Shreedhar. "Smart Farming: IOT Based Smart Sensor Agriculture Stick For Live Temperature And Humidity Monitoring." Available at SSRN 3651933 (2020).

[11] Tao, Wen, et al. "Review of the internet of things communication technologies in smart agriculture and challenges." Computers and Electronics in Agriculture (2021): 106352.

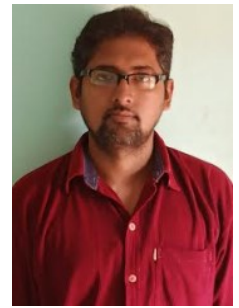

Dr. B. N. Mohapatra was born in Berhampur Village, Berhampur, ODISHA, INDIA in 1985 $\mathrm{He}$ received the B.E. and M.Tech. degrees in Electronics Instrumentation engineering from the University of Berhampur and University of BPUT, Odisha in 2006 and 2011 respectively, and the $\mathrm{PhD}$ degree in Electronics and Communication engineering from Centurion University, Paralakhemundi, INDIA, in 2020. The research area of interest is in Sensor applications as well as interest in Control Systems.

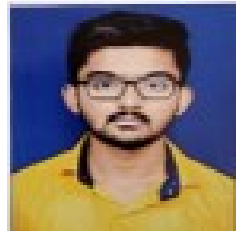

ROHAN VILAS JADHAV was born in Kothurd Village, Pune, Maharashtra, INDIA in 2002. He is pursuing a B.Tech. degree in Instrumentation engineering from AISSMS IOIT in Savitribai Phule Pune University. His research area of interest is in Sensor applications as well as coding for different algorithms.

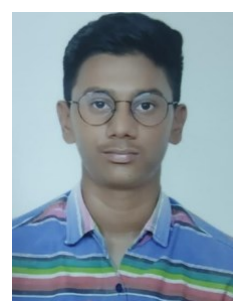

KETAN SUNIL KHARAT was born in Hadapsar Village, Pune, Maharashtra, INDIA in 2003. He is pursuing a B.Tech. degree in Instrumentation engineering from AISSMS IOIT in Savitribai Phule Pune University. His research area of interest is in Sensors and developing IoT based projects.
[12] Roy, Sanku Kumar, et al. "AgriSens: IoT-based dynamic irrigation scheduling system for water management of irrigated crops." IEEE Internet of Things Journal 8.6 (2020): 5023-5030.H. N. Saha, R. Roy, M. Chakraborty, en C. Sarkar, "Development of IoT-Based Smart Security and Monitoring Devices for Agriculture", Agricultural Informatics: Automation Using the IoT and Machine Learning, bll 147-169, 2021

[13] Mohapatra, B. N., and R. K. Mohapatra. "DESIGN OF AN AUTOMATED AGRICULTURAL ROBOT AND ITS PRIME ISSUES." (2020).

[14] Mohapatra, Badri Narayan, et al. "Easy performance-based learning of Arduino and sensors through Tinkercad." International Journal of Open Information Technologies 8.10 (2020).

[15] Mohapatra, Badri Narayan, et al. "Smart Performance of Virtual Simulation Experiments Through Arduino Tinkercad Circuits." Perspectives in Communication, Embedded-systems and Signal-processing-PiCES 4.7 (2020): 157-160.

[16] D. Petrovics en M. Giezen, "Planning for sustainable urban food systems: An analysis of the up-scaling potential of vertical farming", Journal of Environmental Planning and Management, bll $1-27,2021$.

[17] W. Liu, X.-F. Shao, C.-H. Wu, en P. Qiao, "A systematic literature review on applications of information and communication technologies and blockchain technologies for precision agriculture development", Journal of Cleaner Production, bl 126763, 2021.

[18] A. N. Shahu, C. R. Wagh, R. B. Drona, R. A. Suryawanshi, S. Kagne, en S. S. Patil, "Case Study of Smart Farming Using IoT", in Computing Technologies and Applications, Chapman and Hall/CRC, 2021, bll 143-158.

[19] K. Sureeya, C. Karupongsiri, en K. Chetpattananondh, "Implementation of a IR Sensor as a Measurement Device for Smart Farming", in 2021 18th International Conference on Electrical Engineering/Electronics, Computer, Telecommunications and Information Technology (ECTI-CON), 2021, bll 742-745.

[20] M. S. D. Abhiram, J. Kuppili, en N. A. Manga, "Smart farming system using IoT for efficient crop growth", in 2020 IEEE International Students' Conference on Electrical, Electronics and Computer Science (SCEECS), 2020, bll 1-4. 